05

\title{
Магнитоэлектрический эффект в многослойных структурах арсенид галлия никель-олово-никель
}

\author{
( Д.А. Филиппов, ${ }^{1}$ А.А. Тихонов, ${ }^{1}$ В.М. Лалетин, ${ }^{2}$ Т.О. Фирсова, ${ }^{1}$ И.Н. Маничева ${ }^{1}$ \\ ${ }^{1}$ Новгородский государственный университет им. Ярослава Мудрого, \\ 173003 Великий Новгород, Россия \\ ${ }^{2}$ Институт технической акустики НАН Беларуси, \\ 210023 Витебск, Беларусь \\ e-mail: Dmitry.Filippov@novsu.ru
}

(Поступило в Редакцию 19 июня 2017 г.)

\begin{abstract}
Представлены результаты экспериментального исследования магнитоэлектрического эффекта в многослойных структурах никель-олово-никель, полученных гальваническим осаждением на подложку из арсенида галлия. Описана технология изготовления структур и представлена частотная зависимость эффекта. Показано, что использование олова в качестве промежуточного слоя уменьшает механические напряжения, возникающие вследствие несоразмерности фаз на границе никель-арсенид галлия, что позволяет получать качественные структуры с толщиной никелевого слоя порядка $70 \mu \mathrm{m}$. Полученные структуры обладают хорошей адгезией между слоями и имеют высокую добротность.
\end{abstract}

DOI: 10.21883/JTF.2018.02.45407.2391

\section{Введение}

Слоистые композиционные магнитострикционно-пьезоэлектрические материалы привлекают к себе внимание тем, что величина магнитоэлектрического (МЭ) эффекта в них значительно больше, чем в объемных композитах [1]. По сравнению с объемными композитами они обладают малыми токами утечки благодаря тому, что магнитострикционная фаза с более высокой проводимостью изолируется пьезоэлектрической фазой с высоким удельным сопротивлением. При этом в качестве магнитострикционной фазы можно использовать материалы с высокой проводимостью, обладающими бо́льшим коэффициентом магнитострикции. Большинство слоистых магнитострикционно-пьезоэлектрических структур получено методом склеивания фаз. Однако использование клея делает процесс крайне нетехнологичным, кроме того, уменьшается величина эффекта и ухудшается добротность структуры [2]. Большим недостатком клеевых слоистых структур является плохая механическая прочность, расслоение образцов по границам фаз. Это существенно ограничивает практическое применение таких структур.

При выборе материалов для изготовления структур в качестве магнитострикционной фазы обычно выбирают материал с бо́льшим коэффициентом магнитострикции $\lambda$, такие как $\mathrm{Ni}, \mathrm{Co}, \mathrm{FeCo}, \mathrm{FeGa}$, аморфные и редкоземельные сплавы, а в качестве пьезоэлектрической фазы старались использовать материалы с бо́льшим пьезоэлектрическим модулем $d$ (керамика цирконататитаната свинца, кристаллы магниониобата-титаната свинца, крислаллы лангатата, ниобата лития, титаната бария и т.д.) [3,4]. Однако, как показывают расчеты [5], величина МЭ эффекта прямо пропорциональна пьезомодулю и обратно пропорциональна диэлектрической про- ницаемости пьезоэлектрика. Хотя величина пьезомодуля y GaAs почти в 40 раз меньше, чем у ЦТС (GaAs $d=-2.69 \mathrm{pK} 1 / \mathrm{m}$, ЦТС $d=100 \mathrm{pK} 1 / \mathrm{m})$, его диэлектрическая проницаемость в 135 раз меньше, чем у ЦТС (GaAs $\varepsilon=12.9$, ЦТС $\varepsilon=1750)$. Это приводит к тому, что при прочих равных условиях следует ожидать, что величина МЭ эффекта в структурах на основе GaAs будет в 3.5 раза больше, чем в структурах на основе ЦТС. Кроме того, использование арсенида галлия в качестве пьезоэлектрика исключает такую операцию, как предварительная поляризация, которая необходима, если в качестве пьезоэлектрика выбирается пьезокерамика ЦТС.

Впервые МЭ эффект в структуре на основе арсенида галлия исследовался в работе [6]. Авторы ушли от клеевых структур и магнитострикционная фаза (Ni) наносилась на подложку из арсенида галлия методом напыления. Это обеспечивало хороший механический контакт между фазами, но не позволяло получить большое значение эффекта. Как показано в работе [7], максимальное значение эффекта достигается при условии выполнения равенства ${ }^{p} t \sqrt{{ }^{p} Y}={ }^{m} t \sqrt{{ }^{m} Y}$, где ${ }^{p} Y,{ }^{m} Y-$ модули Юнга пьезоэлектрика и магнетика, ${ }^{p} t,{ }^{m} t-$ coответственно их толщины. Модули Юнга пьезоэлектрика и магнетика, как правило, отличаются не более чем в два раза, поэтому максимальное значение эффекта получается при примерно одинаковых толщинах магнетика и пьезоэлектрика. Использование метода электролитического осаждения позволяет получить магнитострикционные слои, толщина которых соизмерима с толщиной пьезоэлектрической подложки. Однако при получении толстых слоев возникает проблема адгезии. В работе [8] с целью улучшения адгезии перед электролитическим осаждением на подложку предварительно напылением наносились подслои. Как показали результаты много- 
численных опытов, для электролитического осаждения никеля на подложку из арсенида галлия лучше всего использовать подслои состава $\mathrm{Au}-\mathrm{Ge}-\mathrm{Ni}$. Толщина каждого подслоя составляла порядка $0.15 \mu \mathrm{m}$. Полученные структуры имели хорошую адгезию, в них наблюдался МЭ эффект, величина которого была соизмерима с величиной эффекта в лучших клеевых образцах на основе ЦТС, но здесь возникла причина остаточных напряжений на границе раздела. Постоянная решетки GaAs равна $0.5633 \mathrm{~nm}$, а у $\mathrm{Ni}$ она равна $0.3524 \mathrm{~nm}$. Это приводит к тому, что при росте толстых слоев в структуре возникают большие механические напряжения. Это существенно снижает механическую прочность образца и даже при небольших механических воздействиях образец разрушается. В настоящей работе с целью уменьшить механические напряжения предлагается вводить буферный слой олова и создавать многослойную структуру никель-олово-никель.

\section{Технология изготовления структур}

Исходные образцы вырезались из пластин арсенида галлия с ориентацией поверхности (100) толщиной в форме параллелепипеда с размерами $14 \times 4 \times 0.4 \mathrm{~mm}$, длинная сторона которых совпадала с направлением $\langle 110\rangle$ кристалла. С целью улучшения адгезии на образцы предварительно напылялись подслои $\mathrm{Au}-\mathrm{Ge}-\mathrm{Ni}$. Перед нанесением гальванических покрытий все образцы вначале контактировали с помощью никелевой проволоки диаметром $0.2 \mathrm{~mm}$. Затем образцы обезжиривали раствором лабомида 203. Для этого использовали раствор с концентрацией лабомида 203 от 30 до $40 \mathrm{~g} / 1$, раствор подогревали до $70-80^{\circ} \mathrm{C}$, а время обезжиривания составляло 10-20 min. После обезжиривания образцы промывали в горячей воде с температурой $60-80^{\circ} \mathrm{C}$ в течение $1 \mathrm{~min}$.

При электролитическом осаждении никеля возникают высокие внутренние напряжения, вследствие чего не удается получить толстые (более $50 \mu \mathrm{m}$ ) слои. С целью повышения пластичности покрытий на основе никеля было решено ввести в такие покрытия прослойки из тонких оловянных слоев. Для нанесения гальванических покрытий использовались электролиты, представленные в таблице.

Для всех электролитов применялся толчок тока, т.е. в начале электролиза катодную плотность тока (кратковременно до $1 \mathrm{~min}$ ) повышали в 2 раза по сравнению с основной рабочей катодной плотностью тока.

При получении многослойной структуры поочередно использовали электролитическое осаждение в сернокислом электролите никелирования № 1, при катодной плотности тока $1 \mathrm{~A} / \mathrm{dm}^{2}$ и температуре электролита $55-65^{\circ} \mathrm{C}$, а затем электроосаждение в электролите лужения № 2 при комнатной температуре и катодной плотности тока $2 \mathrm{~A} / \mathrm{dm}^{2}$. В результате получили многослойную структуру, состоящую из следующих слоев: оловян-
Составы электролитов, использованные для создания структур

\begin{tabular}{l|c|c}
\hline \multicolumn{1}{c|}{$\begin{array}{c}\text { Компоненты } \\
\text { электролита, g/1 }\end{array}$} & $\begin{array}{c}\text { Электролит } \\
\text { № } 1\end{array}$ & $\begin{array}{c}\text { Электролит } \\
\text { № 2 }\end{array}$ \\
\hline $\begin{array}{l}\text { Никель сернокислый } \\
\text { семиводный }\end{array}$ & 250 & - \\
\hline $\begin{array}{l}\text { Никель хлористый } \\
\text { шестиводный }\end{array}$ & 50 & - \\
\hline Олово сернокислое & - & 60 \\
\hline Борная кислота & 25 & - \\
\hline Серная кислота & - & 105 \\
\hline Препарат ОС-20 & - & 4.5
\end{tabular}

ный $-8 \mu \mathrm{m}$, никелевый $-12 \mu \mathrm{m}$, оловянный $-9.6 \mu \mathrm{m}$, никелевый - $12 \mu \mathrm{m}$, оловянный - $38.4 \mu \mathrm{m}$, никелевый $-6 \mu \mathrm{m}$, оловянный $-8 \mu \mathrm{m}$, никелевый $-12 \mu \mathrm{m}$, оловянный $-7.2 \mu \mathrm{m}$, никелевый $-12 \mu \mathrm{m}$, оловянный $9.6 \mu \mathrm{m}$, никелевый - $12.6 \mu \mathrm{m}$, оловянный $-9.6 \mu \mathrm{m}$. Таким образом, получили сэндвич структуру, состоящую из шести слоев никеля, общей толщиной $66.6 \mu \mathrm{m}$ и семи слоев олова, общей толщиной $90.4 \mu \mathrm{m}$. Общая толщина многослойной структуры составила $157 \mu \mathrm{m}$. Покрытие на арсениде галлия получилось ровное, матовое и без видимых дефектов.

\section{Магнитоэлектрический эффект}

Магнитоэлектрический эффект в структуре изучался путем измерения напряжения на образце при помещении его в постоянное (подмагничивающее) и переменное магнитные поля. Вначале исследовалась полевая зависимость низкочастотного МЭ сигнала. При постоянном значении напряженности переменного магнитного поля 1 Ое измерялась зависимость МЭ коэффициента от напряженности подмагничивающего поля. Затем при напряженности поля подмагничивания, соответствующего максимуму эффекта, исследовалась частотная зависимость магнитоэлектрического коэффициента в области электромеханического резонанса. Исследовался продольный эффект, т. е. когда постоянное и переменное магнитные поля были направлены вдоль длинной стороны образца. Особенности МЭ эффекта, когда в качестве пьезоэлектрика используется арсенид галлия, заключаются в том, что отличными от нуля компонентами пьезоэлектрического тензора являются $d_{14}=d_{25}=d_{36}$, и поэтому электрическое напряжение, индуцируемое на обкладках образца, возникает в результате деформаций сдвига, а не деформаций растяжение-сжатие, как в ЦТС. В нашем случае переменное магнитное поле, направленное вдоль длинной стороны образца (ось $X$ ) индуцирует в магнитной компоненте деформации растяжениясжатия, тензор которых в системе координат, связанных 


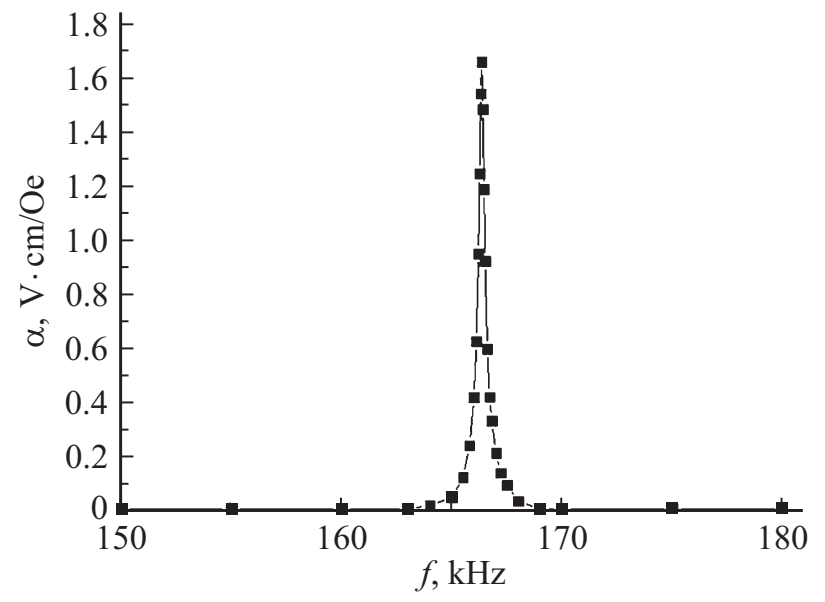

Рис. 1. Частотная зависимость МЭ коэффициента по напряжению в области электромеханического резонанса.

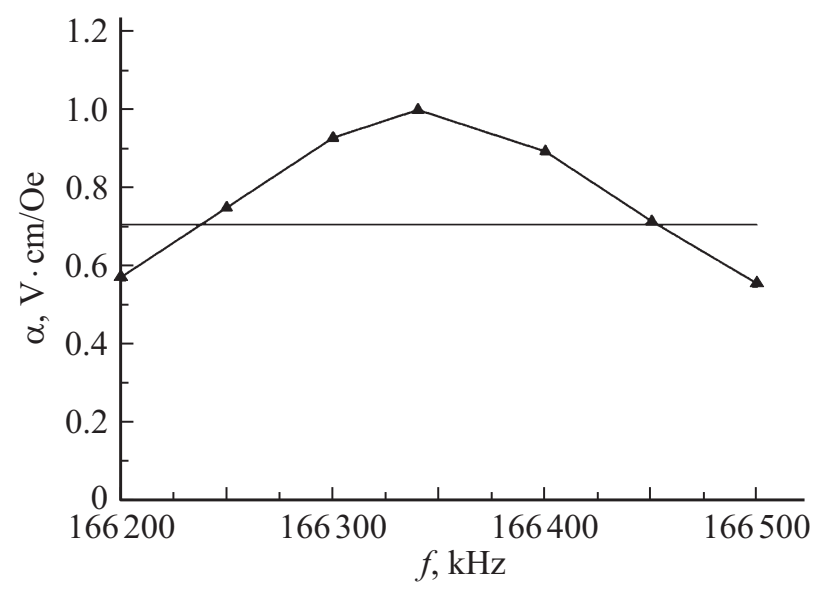

Рис. 2. Частотная зависимость МЭ коэффициента по напряжению вблизи пика резонанса.

с образцом, обозначим через $S_{x x}$. Эти деформации передаются в пьезоэлектрик, длинная сторона которого вырезана в направлении $\langle 110\rangle$, и поэтому в системе координат, связанной с кристаллом $\left(x_{1}, x_{2}, x_{3}\right)$, тензор деформаций будет иметь уже другие компоненты. Используя стандартные преобразования тензоров

$$
S_{i^{\prime} j^{\prime}}=\beta_{i^{\prime} k} \beta_{j^{\prime} i} S_{k l},
$$

несложно показать, что в данном случае отличной от нуля будет компонента тензора деформаций $S_{6}=\beta_{x_{1} x} \beta_{x_{2} x} S_{x x}$, которая и приведет к индуцированию электрического поля. Здесь $\beta_{i^{\prime} k}-$ матрица косинусов между кристаллографической системой координат и системой координат, связанной с кристаллом.

На рис. 1 приведены результаты экспериментальных измерений частотной зависимости МЭ коэффициента по напряжению. Как видно из рисунка, частотная зависимость имеет резкий резонансный характер. Значение МЭ коэффициента по напряжению значительно ниже, чем в чистой структуре никель-арсенид галлия [8], что объясняется наличием пассивного буферного слоя олова. Однако данная структура имеет очень высокую добротность. На рис. 2 представлена частотная зависимость эффекта в области резонанса. Как следует из рисунка, добротность системы $Q=800$, что гораздо лучше добротности образцов, полученных методом склеивания, и сопоставима с добротностью объемных композитов [9].

\section{Заключение}

Таким образом, использование промежуточного слоя олова при электролитическом осаждении никеля на арсенид-галлиевую подложку позволяет получить структуры с толщиной никелевого слоя до 70 мкм. Данные структуры имеют хорошую адгезию между слоями, обладают хорошей механической прочностью, имеют высокую добротность и являются перспективными для создания приборов на основе магнитоэлектрического эффекта.

Работа выполнена при поддержке гранта совместного конкурса РФФИ-БРФФИ: Российский проект № 16-52-00184 и Белорусский проект № Ф16Р-130.

\section{Список литературы}

[1] Srinivasan G. // Annu. Rev. Mater. Res. 2010. Vol. 40. P. $153-178$.

[2] Filippov D.A., Galichyan T.A., Laletin V.M. // Appl. Phys. A. 2014. Vol. 116. P. 2167-2171.

[3] Vopson M. // Critical Reviews in Solid State and Materials Science. 2014. P. 1-28.

[4] Nan C.-W., Bichurin M.I., Dong S., Viehland D., Srinivasan G. // J. Appl. Phys. 2008. Vol. 103. P. 031101.

[5] Filippov D.A., Laletin V.M., Galichyan T.A. // Appl. Phys. A. 2014. Vol. 115. P. 1087-1091.

[6] Лалетин В.М., Стогний А.И., Новицкий Н.Н., Поддубная Н.Н. // Письма в ЖТФ. 2014. Т. 40. Вып. 21. С. 71-77.

[7] Филиппов Д.А., Лалетин В.М., Galichyan Т.А.// ФТТ. 2013. Т. 55. Вып. 9. С. $1728-1733$.

[8] Филиппов Д.А., Фирсова Т.О., Лалетин В.М., Поддубная Н.Н. // Письма в ЖТФ. 2017. Т. 43. Вып. 6. С. 72-77.

[9] Филиппов Д.А., Лалетин В.М., Srinivasan G. // ЖТФ. 2012. Т. 82. Вып. 1. С. 47-51. 